\title{
Role of uterine manipulator during laparoscopic endometrial cancer treatment
}

\author{
Vito Andrea Capozzi ${ }^{1}$, Andrea Rosati ${ }^{2}$, Stefano Uccella ${ }^{3}$, Gaetano Riemma ${ }^{4}$, Mattia Tarascio ${ }^{5}$, \\ Marco Torella ${ }^{4}$, Pasquale De Franciscis ${ }^{4}$, Nicola Colacurci ${ }^{4}$, Stefano Cianci ${ }^{4}$
}

${ }^{1}$ Department of Gynecology and Obstetrics, University of Parma, Parma, Italy; ${ }^{2}$ Unità Operativa Ginecologia Oncologica, Dipartimento Scienze della Salute della Donna e del Bambino, Fondazione Policlinico Univeristario A. Gemelli, IRCCS, Rome, Italy; ${ }^{3}$ Nuovo Ospedale degli Infermi Dipartimento di Oncologia di Biella, Ponderano, Italy; ${ }^{4}$ Department of Woman, Child and General and Specialized Surgery, University of Campania "Luigi Vanvitelli”, Naples, Italy; ${ }^{5}$ Azienda Sanitaria Provinciale di Catania- via S. Maria La Grande, Catania, Italy Contributions: (I) Conception and design: VA Capozzi, A Rosati, S Cianci, G Riemma; (II) Administrative support: All authors; (V) Provision of study materials or patients: S Uccella, G Riemma; (IV) Collection and assembly of data: VA Capozzi, A Rosati, S Uccella; (V) Data analysis and interpretation: M Tarascio, M Torella, P De Franciscis, G Riemma; (VI) Manuscript writing: All authors; (VII) Final approval of manuscript: All authors. Correspondence to: Stefano Cianci, MD, PhD. Department of Woman, Child and General and Specialized Surgery, University of Campania "Luigi Vanvitelli”, Largo Madonna delle Grazie, 180138 Naples, Italy. Email: stefano.cianci@unicampania.it.

\begin{abstract}
Endometrial cancer (EC) is the most frequent gynecologic malignancy with 61,000 new cases diagnosed per year in the USA. Gynecologic Oncology Group (GOG) LAP2 randomized study demonstrated a superimposable 5 -year overall survival between laparotomic and laparoscopic approaches in EC treatment. In this context the uterine manipulator (UM) represents a valuable tool in order to increase the ergonomics of surgical gesture during a laparoscopic total hysterectomy. Despite the proven safety of the minimally invasive approach in EC treatment, neither the indication whether to use or not, nor the recommendation concerning a specific type of UM are provided by international guidelines. This narrative review aims to collect all the main findings in the literature about UM use to investigate its safety in EC patients. Based on the analysis of the literature research, the main results were categorized into two manipulator-related problems: the iatrogenic LVSI, and the retrograde tumor spillage. LVSI is defined as the presence of tumor cells within an endothelium-lined space. An electronic search was performed using the following keywords: 'uterine manipulator', and 'endometrial cancer'. The electronic database search provided a total of 93 studies. Of whom, 12 case reports, 5 studies not in English language, and 65 works not fitting the review scope were excluded from the analysis. Eleven studies were considered eligible for the purpose of the study. The most recent studies have highlighted the safety of the uterine manipulator in the earlystage EC laparoscopic treatment. All types of manipulators are considered to be fairly safe but its application should be tailored according to tumor dimension and grade of myometrial infiltration.
\end{abstract}

Keywords: Uterine manipulator; endometrial cancer (EC); laparoscopy; lymphovascular space invasion (LVSI) mimics; tumor spillage

Submitted May 15, 2020. Accepted for publication Jul 06, 2020.

doi: $10.21037 /$ tcr-20-2094

View this article at: http://dx.doi.org/10.21037/tcr-20-2094

\section{Introduction}

Endometrial cancer (EC) is the most frequent gynecologic malignancy with 61,000 new cases diagnosed per year in the USA (1). Surgical staging procedures including total hysterectomy, bilateral salpingo-oophorectomy, and nodal assessment are the standard treatment in case of apparent uterine-confined disease both in young and elderly patients (2-7). Furthermore, recent data support the sentinel lymph node technique for nodal staging in both low and high-risk EC patients (8-10). 


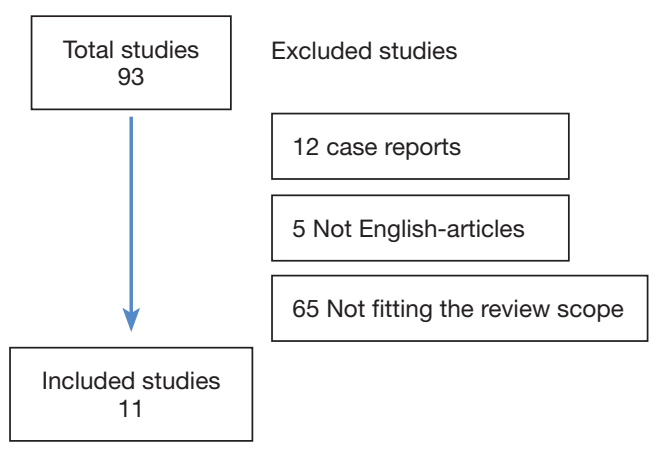

Figure 1 Flow-chart.

After the Gynecologic Oncology Group (GOG) LAP2 randomized study demonstrated a superimposable 5 -year overall survival between laparotomic and laparoscopic approach, with fewer postoperative adverse events and shorter hospital stays in the latter group, minimally invasive surgery has been widely accepted and globally adopted for EC treatment (11-14). Moreover, several authors stressed the importance of surgical mini-invasiveness, the preservation of fertility, and the quality of life on the psychological well-being of gynecological cancer patients $(15,16)$.

Minilaparocopic surgery and novel robotic surgical platforms also demonstrated improvements in the EC patient's quality of life compared to classic laparotomic surgery (17-25).

In this context the Uterine manipulator (UM) represents a valuable tool in order to increase the ergonomics of surgical gesture during a laparoscopic total hysterectomy. $\mathrm{UM}$ increases both the exposure of the vaginal fornix during colpotomy, and, through a cranial and lateral probe pressure, the distance between the ureter and the uterine cervix avoiding ureteral iatrogenic damage (16). Despite the proven safety of minimally invasive approach in EC treatment, neither the indication whether to use or not, nor the recommendation concerning a specific type of UM are provided by international guidelines $(2,26)$.

Furthermore, due to studies showing a potential increased incidence of lymphovascular space invasion (LVSI) related to the use of UM, there was a progressive negative trend in its application in case of uterine malignancies $(27,28)$.

Thus, although most recent studies demonstrated the safety of the UM in EC patients, there are still some concerns about its routinary use (29-31).

This review aims to collect all the main findings in the literature about UM use to investigate its safety in EC patients from an oncological point of view.

The principal objectives of this article are to investigate the correlations between UM application and the incidence of both iatrogenic LVSI and retrograde Fallopian-tube tumor spillage with a particular focus to their impact on oncological outcomes.

\section{Methods}

An electronic search was performed in double-blind by the two authors CVA and RA of all related studies until March 2020. Research on Pubmed, Web of Science, and Scopus was carried out using the following keywords: 'uterine manipulator', 'and', 'endometrial cancer'. Two authors reviewed all extracted abstracts independently. The agreement about potential relevance was reached by consensus of the researchers; After the first selection, the authors evaluated the full-text copies of selected papers and separately extracted relevant data regarding study characteristics and outcomes. All bibliographies were analyzed to find additional eligible studies.

Systematic reviews, meta-analyses, clinical trials, and original articles were included in the present review. Studies considered not in line with the purpose of the study, case reports, articles not in English language were excluded.

The electronic database search provided a total of 93 studies. Of whom, 12 case reports, 5 studies not in English language, and 65 works not fitting the review scope were excluded from the analysis. Eleven studies were considered eligible for the study. The study selection flow-chart was reported in Figure 1.

\section{Discussion and evidence synthesis}

Based on the analysis of the literature research, the main results were categorized into two manipulator-related problems: the iatrogenic LVSI, and the retrograde tumor spillage. Furthermore, the results concerning the type of manipulator used were analyzed.

The studies selected with principal findings are reported in Table 1.

\section{Iatrogenic lymphovascular space involvement}

LVSI is defined as the presence of tumor cells within an endothelium-lined space (32). LVSI has been considered as one of the main prognostic factors influencing the survival and recurrence rate of early-stage EC patients (33). 
Table 1 Main studies analyzed

\begin{tabular}{|c|c|c|c|c|}
\hline Author, years & Design & Cases & Stage & Main results \\
\hline Lee, 2010 & Randomized clinical trial & 110 & IA & $\begin{array}{l}\text { UM did not increase rate of positive peritoneal cytology or } \\
\text { lymphovascular space invasion }\end{array}$ \\
\hline Seifi, 2018 & Retrospective cohort & 104 & $|-| I$ & $\begin{array}{l}\text { The use of a UM does not appear to increase the rate of } \\
\text { pseudovascular invasion }\end{array}$ \\
\hline Tinelli, 2016 & Retrospective cohort & 110 & $\mid-I I$ & $\begin{array}{l}\text { UM for laparoscopic treatment of EC does not increase positive } \\
\text { peritoneal cytology }\end{array}$ \\
\hline Zhang, 2014 & Retrospective case-control & 458 & I-IV & UM for EC is not associated with LVSI or malignant cytology \\
\hline Kitahara, 2009 & Retrospective case-control & 49 & $I-I I$ & $\begin{array}{l}\text { Laparoscopic hysterectomy is associated with a higher rate } \\
\text { of vascular pseudoinvasion. However, we cannot attribute this } \\
\text { phenomenon to mechanical disruption, displacement, and } \\
\text { transport of tumor tissue into vascular spaces by the use of a } \\
\text { UM alone }\end{array}$ \\
\hline Folkins, 2010 & Retrospective case-control & 97 & I-II & $\begin{array}{l}\text { The clinical significance of apparent true vascular space } \\
\text { involvement seen adjacent to artifacts is unclear }\end{array}$ \\
\hline Fanfani, 2011 & Retrospective case-control & 314 & la-lb & $\begin{array}{l}\text { Systematic use of UM does not represent a bias for correct } \\
\text { evaluation of the specimen }\end{array}$ \\
\hline
\end{tabular}

EC, endometrial cancer; UM, uterine manipulator; MM, micrometastasis; ITC, isolated cell tumor; LVSI, lymphovascular space invasion.

Furthermore, adjuvant radiation therapy in early-stage cases is established related to LVSI presence (2).

Although previous studies showed a correlation between UM and increased LVSI rate; Machida et al. (34) confuted this finding by reporting that the application of UM during laparoscopic hysterectomy for EC was not associated with a higher LVSI frequency. Kitahara et al. (27) was the first to introduce the concept of a 'pseudo-LVSI invasion' reporting that the apparent greater presence of LVSI in patients undergoing laparoscopic surgery was due to artifacts during the grossing pathological process rather than a real invasion. Dekker et al. (35) also described how to distinguish pseudoinvasion from 'true' LVSI positivity. The presence of tumor cells near large venous or arterial vessels and perivascular lymphocytes are typical of true infiltration of the lymphovascular spaces. Leaving aside the differences between focal and diffuse LVSI presence, several features have been described as LVSI mimics in the pathological analysis (36,37). The main LVSI mimic is the presence of neoplastic cells within the myometrial clefts and in large widened vessels due to the increased manipulator-related intrauterine pressure (38). This phenomenon is particularly present in gross crumbling tumors, as well as during manipulation with inflated balloon UM. Finally, Frimer et al. (39) investigated the presence of micrometastases (MM) and isolated tumor cells (ITC) with the use of UM during EC surgical treatment. Again, uterine manipulation did not appear to be related to a MM and ITC increase in the 175 patients analyzed, regardless of the type of UM used (Humi, Zumi, Hulka, and V-care devices).

\section{Retrograde tumor spillage}

Some studies have claimed that uterine manipulation can cause retrograde transtubal tumor cells diffusion during laparoscopic hysterectomy resulting in positive peritoneal cytology $(40,41)$. The increase in intrauterine pressure 
with the UM insertion could flake the endometrium and subsequently push the neoplastic cells into the peritoneal cavity through the tubes. Following these hypotheses, over the years the practice of coagulating the tubes before the insertion of the UM has been adopted. The same dilemmas have been posed for the endometriosis and some authors also claim a possible iatrogenic retrograde spillage of cancer cells during hysteroscopy for suspected EC (42-44).

Regardless of the surgical precautions, almost all studies have refuted this hypothesis, and the practice of coagulating the tubes has not proved to be necessary or sufficient to avoid positive peritoneal cytology (44-48). Shinohara et al. (45) in a prospective study evaluating the retrograde dissemination of neoplastic cells during laparoscopic hysterectomy for early-stages EC, reported a risk reduction through the cauterization of fallopian tubes. The Japanese authors assessed the presence of tumor cells in the peritoneal washing fluid performed before the UM insertion and after that the hysterectomy had been completed. Although 13 patients had been enrolled in the study, only one patient showed tumor cells in the peritoneal cavity after UM insertion. Conflicting results have been obtained from extensive research of the literature carried out by Guralp et al. (46). The authors found an approximately $10 \%$ increase in cancer cells in the peritoneal fluid after laparoscopic hysterectomy with UM, but these factors did not change the prognosis of early-stage EC patients. Finally, Lee et al. (47) in a randomized study did not show an increase in peritoneal tumor cells nor an increase in positive LVSI in the 55 patients randomized to the uterine manipulator arm compared to patients treated without UM.

Alternative techniques have also been described for uterine manipulation without uterine probes (49). Anyhow, international guidelines do not recommend coagulation of the tubes before the insertion of the intrauterine device, although peritoneal washing is instead recommended $(2,26)$.

\section{Manipulator type}

Standardization of the exact type of UM to be used in EC cases is missing. The choice often depends on the cancer center or the surgeon's personal experience. Due to these aspects, clinical trials analyzing the same types of uterine probes in different centers are still absent. However, empirically it would be thought that manipulators with an inflatable intrauterine probe such as the Rumi manipulator are less traumatic than manipulators with a metal spiral to be screwed into the cervix $(50,51)$.

Uccella et al. (30) compared the oncological outcomes of
Rumi-Kho (CooperSurgical, Inc., Trumbull, CT), Minelli, Clermont-Ferrand (Karl Storz GmbH \& Co., Tuttlingen, Germany), and Cohen (Sklar Surgical Instruments, West Chester, PA) manipulator without finding differences in the risk of recurrence, specific disease survival, overall survival and site of recurrence between the different UM type. For each patient, evaluation of peritoneal washing before and after UM insertion was performed to identify the cases in which the UM lead to a retrograde spillage of tumor cells.

Finally, the same authors divided the manipulators into two groups concerning the presence or absence of an inflated balloon, but also in this case, no difference was found in the two groups.

Despite these encouraging results, the UM use could increase the technical difficulties of the surgical procedure or lead to non-cancer-related operative complications (52). Uterine mobilization in the presence of android anatomical conformation of the pelvis of some women, or the case of very large uteri, could decrease with the positioning of the UM (53). Furthermore, the cranial push of the uterus after positioning the manipulator would bring the uterine fundus close to the trans-umbilical optics, limiting the vision of the operating field. Although rarely, several related UM positioning complications have been described in the literature. Uterine perforations, device ruptures inside the patient, and vaginal wall lacerations with hemorrhage have been described with the positioning of the RUMI type manipulator (54). While, intestinal perforation, uterine perforation, and pelvic pseudoaneurysm rupture have been described with the Hohl manipulator $(55,56)$.

Undoubtedly, UM use has advantages, but as reported by van den Haak et al. in an extensive review analyzing PubMed, Embase, Web of Science, COCHRANE, CINAHL, Academic Search Premier, Science Direct, and the MAUDE database, the scientific evidence demonstrating the effectiveness and advantages of UM is scarce (57). The same authors, despite the absence of randomized clinical trials, have reported that the Clermont Ferrand type is the manipulator associated with the least complications, easy to use, and that allows good exposure of the operating field. Furthermore as reported, the UM could be useful in iatrogenic or congenital vaginal stenoses (58).

No clinical trial compared the time of a hysterectomy with or without the use of the UM. The mean operating times of a total hysterectomy with UM ranged from 83 to 141 minutes (57). However, $\mathrm{Ng}$ et al., analysis 435 women, emphasized that the operating times and estimated blood losses (EBL) did not depend on the UM use but rather 
on the size of the uterus (59). This study showed that uteri smaller than $5 \mathrm{~cm}$ had a median operating time of 43 minutes with $50 \mathrm{~mL}$ EBL, compared to 136 minutes and $313 \mathrm{~mL}$ EBL for larger uteri. Finally, Macciò et al., in cases of uteri even heavier than $800 \mathrm{~g}$, showed how the manipulator can increase uterine lateralization, allowing better ureteral identification and greater safety during colpotomy time, due to the presence of the manipulator's vaginal cup (60).

To date, the Role of Uterine Manipulator in Hysterectomy - Ro.Man.HY (RoManHy) multicentric prospective randomized Phase III trial (identification N. NCT02762214) is ongoing and could elucidate the role of the ClermontFerrand Uterine Manipulator in the early-stage EC.

\section{Conclusions}

The most recent studies have highlighted the safety of the uterine manipulator in the early-stage EC laparoscopic treatment. The LVSI positivity should be pathologically standardized and the 'pseudo-LVSI invasion' must be considered in all cases where the uterine manipulator is placed.

It is crucial in this perspective to provide accurate clinical information to the pathologist, such as the positioning of the UM, to correctly interpret the LVSI status on definitive histological examination.

Otherwise, Fanfani et al. (29) demonstrate that the application of UM does not represent a bias for the correct evaluation of myometrial infiltration, histotype, and grade of differentiation in the setting of the frozen section analysis.

Tubal coagulation does not seem to decrease the presence of peritoneal neoplastic cells, however, it is a very simple and quick procedure and generally not related to any intraoperative complications.

It has also to be considered that the vast majority of EC patients underwent a hysteroscopic assessment as a milestone of their preoperative work-up. It is now widely accepted that this procedure is not burdened by an increased risk of positive peritoneal cytology thus not requiring any specific countermeasures to avoid retrograde tubal flow.

To date, all types of manipulators are considered to be fairly safe but its application should be tailored according to tumor dimension and grade of myometrial infiltration. We assume that for large lesions with suspected infiltration up to the serosal layer the positioning of UM could be avoided because of the higher risk of uterine perforation.
Additional randomized clinical trials are needed to evaluate the safety of various types of uterine manipulator.

\section{Acknowledgments}

Funding: None.

\section{Footnote}

Provenance and Peer Review: This article was commissioned by the Guest Editor (Antonio Simone Laganà) for the series "Endometrial Cancer" published in Translational Cancer Research. The article was sent for external peer review organized by the Guest Editor and the editorial office.

Conflicts of Interest: All authors have completed the ICMJE uniform disclosure form (available at http://dx.doi. org/10.21037/tcr-20-2094). The series "Endometrial Cancer" was commissioned by the editorial office without any funding or sponsorship. The authors have no other conflicts of interest to declare.

Ethical Statement: The authors are accountable for all aspects of the work in ensuring that questions related to the accuracy or integrity of any part of the work are appropriately investigated and resolved.

Open Access Statement: This is an Open Access article distributed in accordance with the Creative Commons Attribution-NonCommercial-NoDerivs 4.0 International License (CC BY-NC-ND 4.0), which permits the noncommercial replication and distribution of the article with the strict proviso that no changes or edits are made and the original work is properly cited (including links to both the formal publication through the relevant DOI and the license). See: https://creativecommons.org/licenses/by-nc-nd/4.0/.

\section{References}

1. Siegel RL, Miller KD, Jemal A. Cancer statistics, 2019. CA Cancer J Clin 2019;69:7-34.

2. National Comprehensive Cancer Network. Uterine Neoplasms (Version 3.2019). Available online: https// www.nccn.org/professionals/physician_gls/pdf/uterine.pdf. Accessed April 30, 2019.

3. Volpi L, Sozzi G, Capozzi VA, et al. Long term complications following pelvic and para-aortic lymphadenectomy for endometrial cancer, incidence and 
potential risk factors: a single institution experience. IInt J Gynecol Cancer. 2019;29:312-9.

4. Scaletta G, Dinoi G, Capozzi V, et al. Comparison of minimally invasive surgery with laparotomic approach in the treatment of high risk endometrial cancer: A systematic review. Eur J Surg Oncol 2020;46:782-8.

5. Vitale SG, Capriglione S, Zito G, et al. Management of endometrial, ovarian and cervical cancer in the elderly: current approach to a challenging condition. Arch Gynecol Obstet 2019;299:299-315.

6. De Franciscis P, Riemma G, Schiattarella A, et al. Concordance between the Hysteroscopic Diagnosis of Endometrial Hyperplasia and Histopathological Examination. Diagnostics (Basel) 2019;9:142.

7. Vitale SG. The Biopsy Snake Grasper Sec. VITALE: A New Tool for Office Hysteroscopy. J Minim Invasive Gynecol 2020;27:1414-6.

8. Cignini P, Vitale SG, Laganà AS, et al. Preoperative workup for definition of lymph node risk involvement in early stage endometrial cancer: 5-year follow-up. Updates Surg 2017;69:75-82.

9. Vitale SG, Rossetti D, Tropea A, et al. Fertility sparing surgery for stage IA type I and G2 endometrial cancer in reproductive-aged patients: evidence-based approach and future perspectives. Updates Surg 2017;69:29-34.

10. Vitale SG, Valenti G, Gulino FA, et al. Surgical treatment of high stage endometrial cancer: current perspectives. Updates Surg 2016;68:149-54.

11. Walker JL, Piedmonte MR, Spirtos NM, et al. Laparoscopy compared with laparotomy for comprehensive surgical staging of uterine cancer: Gynecologic Oncology Group Study LAP2. J Clin Oncol 2009;27:5331-6.

12. Gueli Alletti S, Perrone E, Cretì A, et al. Feasibility and perioperative outcomes of percutaneous-assisted laparoscopic hysterectomy: A multicentric Italian experience. Eur J Obstet Gynecol Reprod Biol 2020;245:181-5.

13. Capozzi VA, Sozzi G, Gambino G, et al. Laparoscopy versus laparotomy for surgical treatment of obese women with endometrial cancer : a cost-benefit comparative analysis. Mol Clin Oncol 2019;11:335-42.

14. Perrone E, Fanfani F, Rossitto C, et al. Laparoscopic vs percutaneous hysterectomy in obese patients: a prospective evaluation. Facts Views Vis Obgyn 2020;11:307-313.

15. Vitale SG, La Rosa VL, Rapisarda AMC, et al. Fertility preservation in women with gynaecologic cancer: the impact on quality of life and psychological well-being. Hum Fertil (Camb) 2018;21:35-8.
16. Laganà AS, La Rosa VL, Rapisarda AM, et al. Psychological impact of fertility preservation techniques in women with gynaecological cancer. Ecancermedicalscience 2017;11:ed62.

17. Rossitto C, Cianci S, Gueli Alletti S, et al. Laparoscopic, minilaparoscopic, single-port and percutaneous hysterectomy: Comparison of perioperative outcomes of minimally invasive approaches in gynecologic surgery. Eur J Obstet Gynecol Reprod Biol 2017;216:125-9.

18. Rossitto C, Gueli Alletti S, Rotolo S, et al. Total laparoscopic hysterectomy using a percutaneous surgical system: a pilot study towards scarless surgery. Eur J Obstet Gynecol Reprod Biol 2016;203:132-5.

19. Gueli Alletti S, Vizzielli G, Lafuenti L, et al. SingleInstitution Propensity-Matched Study to Evaluate the Psychological Effect of Minimally Invasive Interval Debulking Surgery Versus Standard Laparotomic Treatment: From Body to Mind and Back. J Minim Invasive Gynecol 2018;25:816-22.

20. Gueli Alletti S, Rossitto C, Cianci S, et al. Telelap ALF-X total hysterectomy for early stage endometrial cancer: New frontier of robotic gynecological surgery. Gynecol Oncol 2016;140:575-6.

21. Cianci S, Gueli Alletti S, Rumolo V, et al. Total laparoscopic hysterectomy for enlarged uteri: factors associated with the rate of conversion to open surgery. J Obstet Gynaecol 2019;39:805-10.

22. Gueli Alletti S, Cianci S, Perrone E, et al. Technological innovation and personalized surgical treatment for early-stage endometrial cancer patients: A prospective multicenter Italian experience to evaluate the novel percutaneous approach. Eur J Obstet Gynecol Reprod Biol 2019;234:218-22.

23. Gueli Alletti S, Rossitto C, Cianci S, et al. The Senhance ${ }^{\mathrm{TM}}$ surgical robotic system ("Senhance") for total hysterectomy in obese patients: a pilot study. J Robot Surg 2018;12:229-34.

24. Cianci S, Rosati A, Rumolo V, et al. Robotic Single-Port Platform in General, Urologic, and Gynecologic Surgeries: A Systematic Review of the Literature and Meta-analysis. World J Surg 2019;43:2401-19.

25. Gueli Alletti S, Rossitto C, Cianci S, et al. Telelap ALF-X vs Standard Laparoscopy for the Treatment of Early-Stage Endometrial Cancer: A Single-Institution Retrospective Cohort Study. J Minim Invasive Gynecol 2016;23:378-83.

26. Colombo N, Creutzberg C, Amant F, et al. ESMOESGO-ESTRO consensus conference on endometrial cancer: Diagnosis, treatment and follow-up. Radiother 
Oncol 2015;117:559-81.

27. Kitahara S, Walsh C, Frumovitz M, et al. Vascular Pseudoinvasion in Laparoscopic Hysterectomy Specimens for Endometrial Carcinoma: A Grossing Artifact? Am J Surg Pathol 2009;33:298-303.

28. Krizova A, Clarke BA, Bernardini MQ, et al. Histologic Artifacts in Abdominal, Vaginal, Laparoscopic, and Robotic Hysterectomy Specimens: A Blinded, Retrospective Review. Am J Surg Pathol 2011;35:115-26.

29. Fanfani F, Gagliardi ML, Zannoni GF, et al. Total Laparoscopic Hysterectomy in Early-Stage Endometrial Cancer Using an Intrauterine Manipulator: Is It a Bias for Frozen Section Analysis? Case-control Study. J Minim Invasive Gynecol 2011;18:184-8.

30. Uccella S, Bonzini M, Malzoni M, et al. The effect of a uterine manipulator on the recurrence and mortality of endometrial cancer: a multi-centric study by the Italian Society of Gynecological Endoscopy. Am J Obstet Gynecol 2017;216:592.e1-11.

31. Zhang C, Havrilesky LJ, Broadwater G, et al. Relationship between minimally invasive hysterectomy, pelvic cytology , and lymph vascular space invasion : A single institution study of 458 patients. Gynecol Oncol 2014;133:211-5.

32. Chen M, Jin Y, Bi Y, et al. Prognostic Significance of Lymphovascular Space Invasion in Epithelial Ovarian Cancer. J Cancer 2015;6:412-9.

33. Capozzi VA, Sozzi G, Uccella S, et al. Novel preoperative predictive score to evaluate lymphovascular space involvement in endometrial cancer: an aid to the sentinel lymph node algorithm. Int J Gynecol Cancer 2020;30:806-12.

34. Machida H, Hom MS, Adams CL, et al. Intrauterine Manipulator Use During Minimally Invasive Hysterectomy and Risk of Lymphovascular Space Invasion in Endometrial Cancer. Int J Gynecol Cancer 2018;28:208-19.

35. Dekker TJ, van de Velde CJ, van Bruggen D, et al. Quantitative Assessment of Lymph Vascular Space Invasion (LVSI) Provides Important Prognostic Information in Node-Negative Breast Cancer. Ann Oncol 2013;24:2994-8.

36. Peters EEM, Bartosch C, McCluggage WG, et al. Reproducibility of lymphovascular space invasion (LVSI) assessment in endometrial cancer. Histopathology 2019;75:128-36.

37. Seifi F, Parkash V, Clark M, et al. Pseudovascular Invasion : Minimally Invasive Surgery for Endometrial Cancer. JSLS 2019;23:e201900021.
38. Folkins AK, Nevadunsky NS, Saleemuddin A, et al. Evaluation of vascular space involvement in endometrial adenocarcinomas : laparoscopic vs abdominal hysterectomies. Mod Pathol 2010;23:1073-9.

39. Frimer M, Khoury-Collado F, Murray MP, et al. Gynecologic Oncology Micrometastasis of endometrial cancer to sentinel lymph nodes : Is it an artifact of uterine manipulation? Gynecol Oncol 2010;119:496-9.

40. Sonoda Y, Zerbe M, Smith A, et al. High incidence of positive peritoneal cytology in low-risk endometrial cancer treated by laparoscopically assisted vaginal hysterectomy. Gynecol Oncol 2001;80:378-82.

41. Kashimura M, Sugihara K, Toki N, et al. The Significance of Peritoneal Cytology in Uterine Cervix and Endometrial Cancer. Gynecol Oncol 1997;67:285-90.

42. Uccella S, Manzoni P, Cromi A, et al. Pregnancy After Endometriosis: Maternal and Neonatal Outcomes According to the Location of the Disease. Am J Perinatol 2019;36:S91-8.

43. de Sousa Damião R, Lopes RG, Dos Santos ES, et al. Evaluation of the Risk of Spreading Endometrial Cell by Hysteroscopy: A Prospective Longitudinal Study. Obstet Gynecol Int 2009;2009:397079.

44. Polyzos NP, Mauri D, Tsioras S, et al. Intraperitoneal Dissemination of Endometrial Cancer Cells After Hysteroscopy: A Systematic Review and Meta-Analysis. Int J Gynecol Cancer 2010;20:261-7.

45. Shinohara S, Sakamoto I, Numata M, et al. Gynecology and Minimally Invasive Therapy Risk of spilling cancer cells during total laparoscopic hysterectomy in lowrisk endometrial cancer. Gynecol Minim Invasive Ther 2017;6:113-5.

46. Guralp O, Kushner DM. Iatrogenic transtubal spill of endometrial cancer: risk or myth. Arch Gynecol Obstet 2011;284:1209-21.

47. Lee M, Kim YT, Kim SW, et al. Effects of Uterine Manipulation on Surgical Outcomes in Laparoscopic Management of Endometrial Cancer A Prospective Randomized Clinical Trial. Int J Gynecol Cancer 2013;23:372-9.

48. Tinelli R, Cicinelli E, Tinelli A, et al. Laparoscopic treatment of early-stage endometrial cancer with and without uterine manipulator: Our experience and review of literature. Surg Oncol 2016;25:98-103.

49. Puntambekar SP, Patil AM, Rayate NV, et al. A novel technique of uterine manipulation in laparoscopic pelvic oncosurgical procedures: "the uterine hitch technique". Minim Invasive Surg 2010;2010:836027. 
50. Keriakos R, Zaklama M. The RUMI Manipulator and Koh Colpotomiser System for Total Laparoscopic Hysterectomy. BJOG 2000;107:274-7.

51. Marcos-Sanmartín J, López Fernández JA, Sánchez-Payá J, et al. Does the Type of Surgical Approach and the Use of Uterine Manipulators Influence the Disease-Free Survival and Recurrence Rates in Early-Stage Endometrial Cancer? Int J Gynecol Cancer 2016;26:1722-6.

52. Abdel Khalek Y, Bitar R, Christoforou C, et al. Uterine manipulator in total laparoscopic hysterectomy: safety and usefulness. Updates Surg 2020;72:1247-54.

53. Macciò A, Madeddu C, Kotsonis P, et al. Feasibility and safety of total laparoscopic hysterectomy for huge uteri without the use of uterine manipulator: description of emblematic cases. Gynecol Surg 2018;15:6.

54. Wu HH, Yeh GP, Hsieh TC. Iatrogenic uterine rupture caused by overinflation of RUMI manipulator balloon. J Minim Invasive Gynecol 2005;12:174-6.

55. Akdemir A, Cirpan T. Iatrogenic uterine perforation and bowel penetration using a Hohlmanipulator: A case report.
Int J Surg Case Rep 2014;5:271-3.

56. Seki T, Hamada Y, Ichikawa T, et al. Uterine artery pseudoaneurysm caused by a uterine manipulator. Gynecol Minim Invasive Ther 2017;6:25-7.

57. van den Haak L, Alleblas C, Nieboer TE, et al. Efficacy and safety of uterine manipulators in laparoscopic surgery: a review. Arch Gynecol Obstet 2015;292:1003-11.

58. Cerentini TM, Schlöttgen J, Viana da Rosa P, et al. Clinical and Psychological Outcomes of the Use of Vaginal Dilators After Gynaecological Brachytherapy: a Randomized Clinical Trial. Adv Ther 2019;36:1936-49.

59. Ng CC, Chern BS, Siow AY. Retrospective study of the success rates and complications associated with total laparoscopic hysterectomy. J Obstet Gynaecol Res 2007;33:512-8.

60. Macciò A, Chiappe G, Kotsonis P, et al. Surgical outcome and complications of total laparoscopic hysterectomy for very large myomatous uteri in relation to uterine weight: a prospective study in a continuous series of 461 procedures. Arch Gynecol Obstet 2016;294:525-31.
Cite this article as: Capozzi VA, Rosati A, Uccella S, Riemma G, Tarascio M, Torella M, De Franciscis P, Colacurci N, Cianci S. Role of uterine manipulator during laparoscopic endometrial cancer treatment. Transl Cancer Res 2020;9(12):7759-7766. doi: $10.21037 /$ tcr-20-2094 